\title{
Transitional Dynamics in an R\&D-Based Growth Model with Imitation: Comparing its Predictions to the Data
}

\author{
Fidel Perez-Sebastian* \\ Departamento de Economía \\ Universidad Pública de Navarra \\ 31006 Pamplona, Spain
}

September 3, 1998

\begin{abstract}
Employing cross-country data, this paper evaluates the transitional dynamics predictions of a non-scale growth model of endogenous technology innovation and imitation. We show that, unlike the neoclassical growth framework, the transitional dynamics of the R\&D-based growth model can account for growth "miracles." The additional convergence power provided by technology imitation allows the model to replicate rapid growth experiences for plausible real interest rates, and reasonable consumption and investment shares. Furthermore, our results can reconcile the big contribution of input factor accumulation to economic growth found by Young $(1994,1995$ a) with the importance of technology transfer.
\end{abstract}

Key words: growth, innovation, imitation, transition dynamics

JEL Classification: O40, O30, O11

\footnotetext{
${ }^{*}$ Corresponding author. Tel. \#: (34-48) 169338. Fax \#: (34-48) 169721. E-mail: fidel.perez@unavarra.es.
} 


\section{Introduction}

Recent papers have argued that the Solow growth model performs at least as well as any other candidate for explaining converge experiences. Mankiw, Romer and Weil (1992), Barro and Sala-i-Martin (1992), and Barro, Mankiw, and Sala-i-Martin (1995) find that the model of capital accumulation is consistent with observed crosscountry differences in income levels and growth rates. And Young (1994, 1995a) shows that input factor accumulation has been indeed the main force behind the East Asian Tigers' high economic growth rates. King and Rebelo (1993), however, conclude that the Solow model's transitional dynamics cannot account for important parts of sustained cross-country differences in rates of economic development. The model fails in this respect because it needs either implausibly high interest rates or implausibly low consumption shares in order to generate the type of rapid convergence observed in East Asia. As King and Rebelo (1993) recognize, this finding is especially important because transitional dynamics seem to be a key component of observed growth experiences.

Rapid capital accumulation fostered by diminishing returns is not the only possible explanation for fast economic development. Historians have always argued that technology transfer favored by relatively cheap imitation, what Gerschenkron (1952) called the "advantage of backwardness," is a key driving force behind economic growth. Several papers, which include Barro and Sala-i-Martin (1995, 1997), and Parente and Prescott (1994), have exploited this approach to build models of convergence. The literature, however, has not yet made a serious effort to evaluate the predictions of these models' transitional dynamics. This paper does that. We attack the following questions: Can models with endogenous technical change do better than the neoclassical growth framework in explaining economic transitions? Is the observed big contribution of capital accumulation to economic growth inconsistent with the important role attributed to technology transfer?

We study dynamics in a version of Jones' (1995a) non-scale R\&D-based growth framework. Our main modification is the introduction of technology imitation. Technical progress occurs in the model either by imitating foreign ideas or inventing new ones. Both imitation and innovation are costly, but the former is cheaper. Incorporating imitation greatly increases the model's convergence speed, which is crucial for explaining rapid development experiences. We put the R\&D-based growth model to the toughest test imposed by King and Rebelo (1993) to the Solow framework: we force the model to replicate the Japanese postwar output figures, and evaluate its predictions using cross-country data. We study dynamics using high-degree polynomial

\footnotetext{
${ }^{0}$ A previous version of this paper circulated with the title "Policy and Transitional Dynamics in an R\&I-Based Growth Model." I wish to thank my advisors at the University of Virginia, B. Ravikumar and Aubhik Khan, for helpful discussions. I am also grateful to Elias Dinopoulos, Jane E. Thrig, Robert G. King, Thomas Osang, Chris E. Papageorgiou and Alex Wolman for their comments, and to John Williams for helping me to implement the numerical analysis technique. Finally, I would like to thank seminar participants at the 1996 Southeastern Theory and International Trade Conference, the 1996 Simposio de Análisis Económico, the University of Zaragoza, the University of Salamanca, and the Richmond Fed. Financial support from the University of Virginia and Diputación General the Aragón is gratefully acknowledged.
} 
approximations; in this, we follow the method proposed by Judd (1992).

We choose a non-scale growth model because the empirical evidence suggests that the scale effects predicted by the "classical" R\&D frameworks (Romer, 1990, Grossman and Helpman, 1991, and Aghnion and Howitt, 1992) and by AK models (e.g., Lucas, 1988) are inconsistent with observation. ${ }^{1}$ With respect to other nonscale growth models (e.g., Dinopoulos and Thompson, 1996, Segerstrom, 1995, and Young, 1995b), we choose the Jones-type because it is more appropriate to implement the numerical algorithm.

Transitional dynamics generated by the R\&D model outperform the neoclassical growth framework. Compared to the latter, the advantages of the former model are two. First, the inclusion of a second state variable, the technology level, reduces the marginal productivity of capital (MPK) in technologically backward economies, and therefore permits the generation of reasonable interest rates. Second, the relatively high productivity of imitation at early stages of development provides an additional convergence engine that allows for the fast transitions and large consumption shares shown by East Asian economies, without generating implausibly large investment shares.

Even though in our experiments technology transfer is the most important contributor to the catch-up process, we find that the model predicts a relatively low contribution of total factor productivity (TFP) over most of the adjustment path. For example, starting at a relative level of output of 19 percent, capital accumulation accounts for more than 65 percent of the growth experienced over the first 20 years. The contribution of technology, on the other hand, rises along the path to the steady state. This occurs because, although technology levels in less developed countries are well below the frontier, relative capital input levels are even lower, which is partly due to the capital accumulation induced by the increasing TFP.

Besides King and Rebelo (1993), Christiano (1989) also studies dynamics in the neoclassical growth model. He tries to explain the hump shape displayed by the evolution of the Japanese savings rate during the postwar period. ${ }^{2}$ R\&D-based growth models are analyzed by Benhabib, Perli and Xie (1994), García-Castrillo and Sanso (1997), Gomes (1994), and Williams (1994, 1995). They do not consider technology transfer. Like us, Papageorgiou (1996) and Barro and Sala-i-Martin (1997) analyze R\&D-based growth models that explicitly incorporate technology transfer. But Papageorgiou exclusively focuses on the relationship between economic growth and human capital, and Barro and Sala-i-Martin do not take the model's predictions to the data.

\footnotetext{
${ }^{1}$ Jones (1995a) shows that, in the OECD countries, a higher scale of R\&D input does not increase the growth rate. Backus, Kehoe and Kehoe (1992) also fail to see any evidence of scale effects at the national level. Jones (1995b) and Young (1992) find AK models inadequate in empirical work. Kocherlakota and Yi $(1996,1997)$, however, find some support for the predictions of AK models.

${ }^{2}$ Christiano (1989) succeeds in reproducing the hump shape by giving a Stone-Geary form to the representative agent's preferences. The Stone-Geary form also allows the model to account for the fact that Japan's growth rates actually picked in the early 1960's, and not right after World War II. We do not, however, follow this approach for two reasons. First, the accuracy of the policy function approximations will most likely be very bad - using also an approximation method, Christiano obtains errors of as much as 61 percent. Second, we do not need it to know why the R\&D-based growth model performs better than the Solow model.
} 
Eicher and Turnovsky (1997) also analyze dynamics in non-scale growth models, but they focus on the speed of convergence implied by the linearized system.

We proceed as follows. Section 2 presents the model. The central planner's problem and the steady state are discussed in section 3. Section 4 explains the methodology used to numerically solve the model, and presents both the international data and the transitional dynamics results. Section 5 concludes.

\section{The Model.}

The decentralized structure of the model is the standard in non-scale three sector growth models (e.g., Jones, 1995a). We consider an economy in which the labor force increases at rate $n$. There are three types of activities: consumption goods production, intermediate goods manufacturing, and R\&D investment. The latter is intended to learn new designs for new types of producer durables, being the source of technological progress in the model. When a new design is learned, an intermediate goods producer acquires the perpetual patent over the design. This allows the firm to manufacture the new variety, and practice monopoly pricing. ${ }^{3}$

We omit the details of the decentralized setup, and concentrate on the centrally planned economy, using social production functions in which externalities are internalized. We choose the social optimum because it simplifies the exposition of the paper and because in practice governments have typically supported the accumulation of knowledge. Examples include: public education, technical advisory services for potential adopters, training programs for scientists and engineers, and the establishment of industrial research laboratories. Moreover, casual empiricism points out that these policies were a vital element in the east Asian countries' growth miracles. Freeman (1988), for example, emphasizes that the advisory services provided by the Japanese Ministry of International Trade and Industry (MITI) substantially accelerated the adoption of western technologies, contributing to Japan's economic miracle. He also talks about the existence in Japan of nearly 200 public laboratories that offer research and technical advisory services to small- and medium-size firms. Romer (1992) argues that government policies to promote the introduction of foreign ideas were crucial in Taiwan's growth miracle. There is evidence as well that Asian governments widely increased investment in extension services during the 50's to facilitate the adoption of foreign agricultural technologies (Pray and Ruttan (1990)).

Before stating the central planner's problem, we shall analyze one aspect of the model that is of particular interest, the R\&D technology.

The aggregate production function takes the Cobb-Douglas form,

$$
Y_{t}=A_{t}^{\xi} L_{t}^{\alpha} K_{t}^{1-\alpha}, \quad \xi>0,0<\alpha<1 ;
$$

where $Y_{t}$ and $L_{t}$ are the amounts of output produced and labor at time $t$, respectively; $K_{t}$ is the country's stock of physical capital at date $t$, that is, the sum of all producer

\footnotetext{
${ }^{3}$ As in Barro and Sala-i-Martin (1997), producers are assumed to be unable to circumvent the local monopoly by importing intermediate goods from the rest of the world.
} 
durables units; and $A_{t}$ is the economy's technological level or, in other words, the mass of producer durables varieties that have been already learned by date $t$. $Y_{t}$ can be interpreted as the Gross Domestic Product of the economy.

The technological level can be improved either by inventing new types of intermediate goods or by imitating them from an international pool of ideas. We assume that the size of the international pool increases exogenously at rate $g_{A_{w}}$. The increase in the total amount of producer durables varieties used in production at a given point in time $t$ is given by the following aggregate "lab-equipment" R\&D technology:

$$
A_{t+1}-A_{t}=\mu A_{t}^{\phi}\left\{R_{I t}^{\lambda}+\left[R_{C t}\left(\frac{\eta A_{w t}}{A_{t}}\right)^{\rho}\right]^{\lambda}\right\}, 0<\lambda<1, \eta>0, \rho>0
$$

where $A_{w t}$ is the time- $t$ worldwide stock of all ideas that can be used in production if they are learned, regardless of where they originated; and $R_{I t}$ and $R_{C t}$ are the amounts of output that the economy invests in innovation and imitation at date $t$, respectively. This means that the $R \& D$ input is produced with the same technology as consumption goods, equation (1); capital and labor are just shifted from production of final goods into production of new designs. Notice that $A_{t}$ must be less than or equal to $A_{w t}$ at each date $t$. This R\&D technology is an extension of the innovation technology proposed by Jones (1995a) into which we have introduced imitation. In equation (2), if $\phi>0$, there is a positive externality from learning new designs today to future learning productivity - the "intertemporal knowledge spillover" case. When $\phi<1$, there are diminishing technological opportunities, and the economic growth rate becomes exogenous. The parameter $\lambda$ controls for the fact that two or more researchers can come up with the same idea either by chance or because of $R \& D$ races. Since $0<\lambda<1$, a "congestion externality" or, in other words, duplication of effort is present.

In equation (2), the term in square brackets captures the effect of imitation in the economy's technical progress. Local firms invest resources in order to absorb the information needed to replicate new products invented abroad. It differs from innovation in that the number of goods that can be copied at any point in time is limited to the finite number that have been discovered elsewhere. ${ }^{4}$ The specification incorporates an advantage of "backwardness," and is similar to the one in Parente and Prescott (1994) and in Barro and Sala-i-Martin (1995, 1997). We are assuming that the cost of imitating foreign designs decreases as the worldwide stock gets relatively

${ }^{4}$ This implies the following constraint, which we do not impose:

$$
A_{w t} \geq A_{t}+\mu A_{t}^{\phi}\left[R_{C t}\left(\frac{\eta A_{w t}}{A_{t}}\right)^{\rho}\right]^{\lambda} .
$$

We then need to assume that $\eta$ is sufficiently small, but this assumption has no effect on the interior solution optimal allocations. Notice that the constrain will never be binding if $A_{w t}>A_{t+1}$, that is, if $\left[A_{w 0} \frac{\left(1+g_{A_{w}}\right)^{t}}{A_{t+1}}\right]>1$. The ratio $\frac{\left(1+g_{A_{w 1}}\right)^{t}}{A_{t+1}}$ has a lower bound greater than zero because $A_{w t} \geq A_{t}$ in every period, and therefore $A_{t}$ can grow at a rate larger than $g_{A_{w}}$ only temporarily, until it reaches the steady state. Additionally, the interior solution optimal allocations are a function of $K_{0}, L_{0}, A_{0}$, $n, g_{A_{w}}$, and of $\eta$ times $A_{w 0}$. For any optimal $\left\{A_{t}\right\}_{t=0}^{\infty}$, we can then always pick a sufficiently large $A_{w 0}$ for which the above condition holds if we assume that $\eta$ is sufficiently small. 
larger. The idea is that products that are easier, and therefore cheaper to imitate, are copied first; these could be the ones whose technical specifications are relatively simpler. As these "cheaper" intermediate goods are absorbed, the cost of copying an additional design will increase or, in other words, the imitation effort average productivity will decline. This technology also allows imitation to become more expensive than innovation. A value of $\eta$ less than one would imply that some foreign ideas' technical specifications are very complex, and the cost of absorbing them is relatively high compare to the cost of inventing a new one. Since $A_{t}$ is in the denominator, our formulation of the imitation technology displays "diminishing imitation opportunities," which imply a negative externality from current R\&D investment to future imitation productivity; higher levels of R\&D effort today may decrease the relative size of the international pool of ideas, thus making copying more costly in the future.

The way that we have introduced imitation captures two kinds of empirical findings. First, copying tends to be cheaper than innovation (Mansfield et al. (1981)). In our setup, the average productivity of learning is higher in the former activity than in the latter for a sufficiently big international knowledge pool. Second, the ability to take advantage of new ideas available in the rest of the world increases with a country's technological level (Romer (1993) and Eaton and Kortum (1995)). Note that our model is consistent with this stylized fact provided that $\phi-\rho \lambda>0$.

There are at least two ways in which domestic innovation and the foreign pool can be related. First, a portion of innovation effort can be directed to "reinventing the wheel," without contributing to increase worldwide knowledge. In other words, domestic firms may want to build their own version of some foreign products. Second, innovation may also yield new goods that will add up to the international pool of designs. If the second case is relatively important, the size of the international pool will depend on domestic research effort. This will not be the case however for low levels of economic development because at this stage innovation investment is relatively small. For simplicity, we abstract from this effect.

\section{The Planner's Problem and the Steady State}

Let $C_{t}$ be the amount of aggregate consumption at date $t$. A central planner would choose the sequences $\left\{K_{t}, R_{C t}, R_{I t}, C_{t}\right\}_{t=0}^{\infty}$ so as to maximize the lifetime utility of the representative consumer subject to the feasibility constraints of the economy, the time path of the international pool of designs, and the initial values $L_{0}, K_{0}, A_{0}$, and $A_{w 0}$. The problem can be stated as follows:

$$
\begin{gathered}
\max _{\left\{C_{t}, R_{I t}, R_{C t},\right\}} \sum_{t=0}^{\infty} \beta^{t}\left[\frac{\left(\frac{C_{t}}{L_{t}}\right)^{1-\sigma}-1}{1-\sigma}\right] \\
\text { s.t. : } Y_{t}=A_{t}^{\xi} L_{t}^{\alpha} K_{t}^{1-\alpha} \\
K_{t+1}-(1-\delta) K_{t}=Y_{t}-C_{t}-R_{I t}-R_{C t}
\end{gathered}
$$




$$
\begin{gathered}
A_{t+1}-A_{t}=\mu A_{t}^{\phi}\left\{R_{I t}^{\lambda}+\left[\left(\frac{\eta A_{w t}}{A_{t}}\right)^{\rho} R_{C t}\right]^{\lambda}\right\} \\
\frac{A_{w t+1}}{A_{w t}}=1+g_{w}, \text { for all } t \\
\frac{L_{t+1}}{L_{t}}=1+n, \text { for all } t
\end{gathered}
$$

$$
L_{0}, K_{0}, A_{0}, A_{w 0} \text { given; }
$$

where $\beta$ is the discount factor; and $\delta$ is the depreciation rate of capital. Equation (4) is the economy's budget constraint as well as the law of motion of the capital stock; it says that, at the aggregate level, domestic output must equal consumption plus R\&D investment plus physical capital investment.

The FOC to the above problem with respect to aggregate consumption gives its optimal motion,

$$
\left[\frac{C_{t+1}}{C_{t}(1+n)}\right]^{\sigma}=\left(\frac{\beta}{1+n}\right)\left(1+r_{t+1}\right) ;
$$

where $r_{t}$ is the interest rate at time $t ; r_{t}$ equals the MPK,

$$
r_{t}=(1-\alpha) A_{t}^{\xi} L_{t}^{\alpha} K_{t}^{-\alpha}-\delta .
$$

Condition (7) is standard. It implies that, at the optimum, the gross growth rate of the utility value of consumption per capita must equal the discounted MPK, taking into account population growth. That is, individuals must be indifferent between consuming one additional unit of output today and investing it, consuming the proceeds tomorrow.

The concavity of the production and R\&D technologies guarantees that output will be distributed evenly over all activities. Both innovation and imitation will coexist in equilibrium as long as the pool of ideas that can be copied is not empty. The FOCs with respect to the two R\&D activities imply that the socially optimal ratio of imitation to innovation is

$$
\frac{R_{C t}}{R_{I t}}=\left(\frac{\eta A_{w t}}{A_{t}}\right)^{\frac{\rho \lambda}{1-\lambda}} .
$$

As the economy catches up with the technology frontier, imitation becomes relatively less productive, increasing the share of $R \& D$ investment that goes to invent new types of producer durables.

Let $R_{t}$ be the total amount of resources invested in $\mathrm{R} \& \mathrm{D}$; that is, the sum of $R_{C t}$ and $R_{I t}$. We define $T_{t}$ to be the modified ratio of the international stock of ideas to ideas already in use; thus $T_{t}=\frac{\eta A_{w t}}{A_{t}}$. From (9) and (2), we can write the motion equations of the technology level and the capital stock as follows:

$$
A_{t+1}-A_{t}=\mu A_{t}^{\phi} R_{t}^{\lambda}\left[1+T_{t}^{\frac{\rho \lambda}{1-\lambda}}\right]^{1-\lambda}
$$




$$
K_{t+1}-(1-\delta) K_{t}=Y_{t}-C_{t}-R_{t} .
$$

Using (9) and the FOC with respect to either innovation or imitation effort, we obtain the Euler equation that governs the dynamics of the optimal R\&D investment,

$$
\begin{aligned}
{\left[\frac{C_{t+1}}{C_{t}(1+n)}\right]^{\sigma}=} & \frac{\beta}{(1+n)}\left[\frac{\lambda\left(A_{t+1}-A_{t}\right)}{R_{t}}\right] * \\
& *\left\{\frac{R_{t+1}}{\lambda\left(A_{t+2}-A_{t+1}\right)}\left[\frac{A_{t+2}-A_{t+1}}{A_{t+1}}\left(\phi-\rho \lambda \frac{T_{t+1}^{\frac{\rho \lambda}{1-\lambda}}}{1+T_{t+1}^{\frac{\rho \lambda}{1-\lambda}}}\right)+1\right]+\frac{\xi Y_{t+1}}{A_{t+1}}\right\}
\end{aligned}
$$

This condition is equivalent to the one for consumption. At the optimum, individuals must be indifferent between consuming one additional unit of output today and investing it in R\&D, consuming the proceeds tomorrow. The RHS now represents the discounted social marginal productivity of investing in R\&D, taking into account population growth. One additional unit of output invested today in R\&D will increase tomorrow's technology level by $\frac{\lambda\left(A_{t+1}-A_{t}\right)}{R_{t}}$. The parameter $\lambda$ captures the negative effect of diminishing returns in learning due to duplication of effort. The central planner also takes into account the impact on future productivity. One additional variety of producer durables today implies that tomorrow's final output will rise by $\frac{\xi Y_{t+1}}{A_{t+1}}$, and that the composite effect on future R\&D productivity will be $\frac{R_{t+1}}{\lambda\left(A_{t+2}-A_{t+1}\right)}\left[\frac{A_{t+2}-A_{t+1}}{A_{t+1}}\left(\phi-\rho \lambda \frac{T_{t+1}^{\frac{\rho \lambda}{1-\lambda}}}{1+T_{t+1}^{\frac{\rho \lambda}{1-\lambda}}}\right)+1\right]$. The term $\rho \lambda \frac{T_{t}^{\frac{\rho \lambda}{11-\lambda}}}{1+T_{t}^{\frac{\rho \lambda}{1-\lambda}}}$ measures the negative externality from diminishing imitation opportunities; the parameters $\phi$ proxies for possible intertemporal knowledge spillovers; finally, future growth $\frac{A_{t+2}-A_{t+1}}{A_{t+1}}$ and the inverse of tomorrow's R\&D marginal productivity $\frac{R_{t+1}}{\lambda\left(A_{t+2}-A_{t+1}\right)}$ weight the incidence of these externalities.

The system of difference equations composed of Euler conditions (7) and (12), and the laws of motion (5), (6), (10) and (11) characterize the equilibrium allocations in the model. Next, we restrict our attention to the perfect-foresight equilibrium balanced growth path in which the growth rates of all variables in the model are constant. Let $G_{x}$ be the gross growth rate of variable $x$ along the balanced growth path, and define $g_{x}$ as $G_{x}-1$. The usual argument about the constancy of the capital output ratio means that output and physical capital must grow at the same rate (i.e., $g_{K}=g_{Y}$ ). Looking at equation (1), we see that the output growth rate is then determined by the effective-labor growth rate. Appendix A shows that, at steady state, the number of producer durables employed in the economy must grow at the same rate as the international pool, $g_{A}=g_{A_{w}}$; $T_{t}$ then remains constant along the balanced growth path.

From Jones (1995a), we know that the steady state growth rate of per capita output and the interest rate are exogenous, exclusively pinned down by the production and R\&D technologies. Appendix A proves that equations (1) and (10) imply that 
the growth rate of output is given by

$$
G_{Y}=(1+n)^{\frac{1-\phi}{1-\phi-\lambda \frac{\xi}{\alpha}}}
$$

Equations (7) and (13), in turn, give us the steady state interest rate

$$
r_{s s}=(1+n)^{\frac{\sigma \lambda \frac{\xi}{\alpha}}{1-\phi-\lambda \frac{\xi}{\alpha}}+1}\left(\frac{1}{\beta}\right)-1 .
$$

Expression (13) has the following implications: (i) the model does not display scale effects on the steady state growth rates; and (ii) policy only has level effects. Growth effects are however possible along the transition.

From equations $(7),(10)$ and (12), it is easy to show that the share of output going to $\mathrm{R} \& \mathrm{D}\left(S_{R}\right)$ is constant along the balanced growth path, and equal to

$$
S_{R, s s}=\frac{\lambda \xi g_{A}}{\left(1+r_{s s}\right) \frac{G_{A}}{G_{R}}-1-g_{A}\left(\phi-\rho \lambda \frac{T_{s s}^{\frac{\rho \lambda}{1-\lambda}}}{1+T_{s s}^{\frac{\rho \lambda}{1-\lambda}}}\right)}
$$

where ss denotes steady state values. The above arguments and the economy's budget constraint imply that consumption and R\&D investment will also grow at the same rate as output. That is, $g_{Y}=g_{K}=g_{C}=g_{R}$.

\section{Calibration and Dynamics.}

In analyzing the transitional dynamics equilibrium allocations, it is useful to redefine growing variables such that the resulting normalized ones reach a steady state. As we have seen, the effective-labor growth rate determines the output growth rate. We then choose $A_{t}^{\frac{\xi}{\alpha}} L_{t}$ as the normalization factor for the variables of the model. Denote normalized variable $D_{t}$ by $\hat{D}_{t}=\frac{D_{t}}{A_{t}^{\frac{\xi}{\alpha}} L_{t}}$. Normalized variables are measured in per capita-efficiency units. We also define

$$
\theta=\mu\left(\eta A_{w t}\right)^{\phi-1+\lambda \frac{\xi}{\alpha}} L_{t}^{\lambda} .
$$

Because $g_{A_{w}}=g_{A}$, equation (13) implies that $\theta$ is a constant coefficient. In terms of normalized variables, the equilibrium is the set of sequences of prices and normalized allocations $\left\{\hat{K}_{t}, \hat{R}_{t}, \hat{C}_{t}\right\}_{t=0}^{\infty}$ satisfying the optimallity and equilibrium conditions. From equations $(5),(6),(7),(10),(11)$ and (12), the system of difference equations that solve the social planning problem is now the following:

$$
\hat{C}_{t+1}=\frac{\left[\beta\left(1+\frac{1-\alpha}{\hat{K}_{t+1}^{\alpha}}-\delta\right)\right]^{\frac{1}{\sigma}} \hat{C}_{t}}{G_{A t}^{\frac{\xi}{\alpha}}(1+n)^{\frac{1}{\sigma}}}
$$

\footnotetext{
${ }^{5}$ We need to require that $1-\phi>\lambda \frac{\xi}{\alpha}$. Otherwise, no balanced growth path exists.
} 


$$
\begin{gathered}
\left(\frac{\hat{R}_{t+1}}{1+T_{t+1}^{\frac{\rho \lambda}{1-\lambda}}}\right)^{1-\lambda}+\theta T_{t+1}^{1-\phi-\lambda \frac{\xi}{\alpha}} \hat{R}_{t+1}\left(\phi-\frac{\rho \lambda T_{t+1}^{\frac{\rho \lambda}{1-\lambda}}}{1+T_{t+1}^{\frac{\rho \lambda}{1-\lambda}}}\right)= \\
=\left(1+\frac{1-\alpha}{\hat{K}_{t+1}^{\alpha}}-\delta\right) G_{A t}^{\phi-\frac{\xi}{\alpha}(1-\lambda)}\left[\frac{\frac{\hat{R}_{t}}{(1+n)}}{1+T_{t}^{\frac{\rho \lambda}{1-\lambda}}}\right]^{1-\lambda}-\lambda \xi \theta T_{t+1}^{1-\phi-\lambda \frac{\xi}{\alpha}} \hat{K}_{t+1}^{1-\alpha} \\
\hat{K}_{t+1} G_{A t}^{\frac{\xi}{\alpha}}(1+n)=\hat{K}_{t}^{1-\alpha}-\hat{C}_{t}-\hat{R}_{t}+(1-\delta) \hat{K}_{t} \\
T_{t+1}=\left(\frac{1+g_{w}}{G_{A t}}\right) T_{t}
\end{gathered}
$$

where

$$
G_{A t}=\theta T_{t}^{1-\phi-\lambda \frac{\xi}{\alpha}}\left(\frac{\hat{R}_{t}}{1+T_{t}^{\frac{\rho \lambda}{1-\lambda}}}\right)^{\lambda}\left(1+T_{t}^{\frac{\rho \lambda}{1-\lambda}}\right)+1
$$

The equilibrium allocations are described by the decision rules, or policy functions. The model however does not deliver closed form solutions for them. Linearizing the system around the steady state is not useful because our goal is to study the transitional dynamics for state space points that lie far away from the steady state. We therefore choose to numerically approximate the solutions. In what follows, we first describe the methodology and pick the parameters' values used to carry out the experiments. Next, we present the results.

\subsection{Approximation.}

Following Judd (1992), we use high-degree polynomials in the state variables to replicate the policy functions. The parameters of the approximated decision rules are chosen to (approximately) satisfy the Euler equations over a number of points in the state space, using a nonlinear equation solver. A Chebyshev polynomial basis is used to construct the policy functions, and the zeros of the basis form the points at which the system is solved; in other words, we use the method of orthogonal collocation to choose these points. Finally, tensor products of the states variables are employed in the polynomial representations. This method has proven to be highly efficient in similar contexts. ${ }^{6}$ For example, for the one-sector growth model, Judd (1992) finds that the approximated values of the control variables disagree with the values delivered by the true policy functions by no more than one part in 10,000 .

For most models, however, we cannot directly assess how well the polynomial basis approximates the true solution; but there are indirect measures. For instance, as Judd (1992) argues, we can asses the Euler equation error over a large number of points using the approximated rules. For example, if we employ Euler equation (15),

\footnotetext{
${ }^{6}$ See Judd (1992), and Williams (1994, 1995).
} 
the measure will give the current consumption decision error that agents using the approximated rules make, assuming that the (true) optimal decisions were made in the previous period. The accuracy rises with the degree of the polynomials. This improvement, however, declines with the polynomial degree, whereas the computational time increases exponentially. To run our simulations, we used polynomials of degree eight. Higher degrees gave more accuracy, but the results were almost identical. Table 1 reports the maximum and average Euler equation errors found over a grid search of 10,000 state space points for the cases analyzed in the paper. The errors are measured in percentage terms. Even though in our experiments we start from a relative below-trend level of output of $19 \%$, the accuracy of the approximations is remarkable. With respect to the optimal consumption rule, the maximum and average errors were never greater than 0.4 and 0.09 percent, respectively. The R\&D solution approximation never gave average and maximum errors greater than 0.8 and 3.5 percent, respectively, and except for one case the maximum error was always below 1.6 percent. ${ }^{7}$

\subsection{Calibration.}

Table 2 shows the parameter values used to carry out our simulations. We assign values of 0.36 to the capital-share of output $(1-\alpha), 0.96$ to the discount factor $(\beta)$, and 0.1 to the depreciation rate $(\delta)$. These values are typical in neoclassical growth model research. We set the growth rate of the population $(n)$ to $1.4 \%$ per year, which is the average value for the United States during the period 1950-1980. Estimates of the inverse of the intertemporal elasticity of substitution between present and future consumption go from 1 to 3.5 (Hall (1988), and Attanasio and Weber (1993)); we run the experiments for two different values: $\sigma=1$, which is the benchmark case in King and Rebelo (1993); and $\sigma=2$, an intermediate value. Appendix B shows that the decentralized setup implies that $\xi=(m-1)(1-\alpha)$; where $m$ is the mark-up ratio charged by intermediate goods producers. Hence, assigning a value to the elasticity of output with respect to the technological level is equivalent to choosing a value for the mark-up. From Domowitz, Hubbard and Petersen (1988), we take a mark-up ratio of $1.35 .^{8}$

The calibration of the R\&D technology parameters is more problematic. There are not reliable estimates of $\lambda$. Williams (1995) provides some preliminary evidence that $\lambda$ takes on values between 0.5 and 0.75 . Jones and Williams (1996) find that a value of 0.48 is a possible lower bound for $\lambda$. Dinopoulos and Thompson $(1995,1996)$ obtained estimates in a range $0.17-0.38$. Finally, Kortum (1992) obtains values for

\footnotetext{
${ }^{7}$ The policy functions were approximated using the functional form:

$$
\ln D_{t}=\Psi_{8}\left(\ln T_{t}, K_{t}\right), \quad D_{t}=C_{t}, R_{t} ;
$$

were $\Psi_{n}$ denotes the $n$ th-degree Chebyshev polynomial function. The program was written in gauss386 , and is available upon request.

${ }^{8}$ They estimate a producer durable markup ratio using electronic and electric equipment data. Furthermore, they adjust it to separate out fixed costs, which are completely absent in our model. The same mark-up value is also used in a very similar framework by Williams $(1994,1995)$.
} 
a parameter like $\lambda$ of about 0.2 . Given that the literature does not provide much guidance, we carry out a sensitivity analysis, and present results for $\lambda$ equal $0.25,0.5$, and 0.75 . Estimates of $\phi$ can be obtained as a function of $\lambda$ and $\xi$; in this, we follow Jones and Williams (1996). We can use the fact that both TFP growth $\left(\bar{g}_{T F P}\right)$ and R\&D expenditure growth $\left(\bar{g}_{R}\right)$ have been relatively constant over the postwar period in the United States at rates 0.0183 and 0.0475 , respectively. ${ }^{9}$ Since in our model $G_{T F P}$ is equivalent to $G_{A}^{\xi}$, expression (10) implies that (see Appendix A):

$$
\phi=1-\lambda \xi \frac{\log \left(1+\bar{g}_{R}\right)}{\log \left(1+\bar{g}_{T F P}\right)} .
$$

Appendix B shows that the steady state value of the relative international pool of designs $\left(T_{s s}\right)$ equals the ratio of imitation to innovation public support. ${ }^{10}$ Based on agricultural data presented in Table 3 , the ratio of extension (or imitation) to research (or innovation) support reaches for the developed world a possible steady state value of 0.41 . This is the value that we assign to $T_{s s}$. There are not any empirical estimates of parameter $\rho$. We pick the value of $\rho$ for which the planning solution best fits the Japanese output data, taking as given the rest of parameters' values. In particular, we use the fact that Japan' per capita output moved from 19 percent of U.S. output to 74 percent during 1950 to 1980 .

Using the steady state allocations in the command optimum, we directly obtain the remaining model's parameters from the above ones. For the calibrated parameters, the steady state annual rate of growth of per capita output is 2.2 percent. The balanced growth path real interest rate equals 8 percent if $\sigma=1$, and 10.3 percent if $\sigma=2$.

\subsection{Simulation Results}

The purpose of this section is two fold. First, we want to assess the contributions of technological change and capital accumulation to per capita output growth. Second, we want to compare the predictions of the R\&D model's transitional dynamics to the ones of the neoclassical growth framework. To do this, we look at the equilibrium behavior in response to two simultaneous shocks, one to each state variable. For the size of the shock to the stock of physical capital, we follow Christiano (1989). Extrapolating from pre-World War II data, he estimates that the Japanese capital stock in 1946 was only 12 percent of its pre-war steady state value; thus, we take $\widehat{K}_{\mathbf{0}}=0.12$. In turn, we pick the shock to the relative size of the international knowledge pool so as to make per capita output 19 percent of its steady state level.

\footnotetext{
${ }^{9}$ The former number is the average TFP growth rate for the manufacturing sector, and is taken from the Bureau of labor Statistics, U.S. Department of labor (1991). The latter figure is the average growth rate of real industry-financed and conducted R\&D, and is computed by Jones and Williams (1996) using a variety of sources.

${ }^{10} T_{s s}$ also determines the country's technology dependency ratio. We opt for the other alternative because advanced countries, like the United States and Japan, that seem to be very close to the technological frontier have very different dependency ratios, and our model cannot account for this phenomenon.
} 
Assuming that the US was in steady state in 1950, this implies initial values for the capital stock per capita and TFP of 4.9 percent and 56.3 percent of the U.S. level, respectively. We run simulations for the six triples $(\sigma, \lambda, \rho)$ that deliver social solutions consistent with Japan's convergence speed (see Table 2 ).${ }^{11}$

Besides the Japanese, are those values relevant for other possible development experiences? Isn't the capital stock too low compared to TFP? Extrapolating from estimates computed by Jones (1996, Appendix Table), Figure 1 plots the relative levels of the Solow residual and the capital stock per capita in 1990 for 84 countries. It turns out that, in most cases, relative capital levels are much lower than their technology counterparts. Compared to the plotted sample, our initial values, given in Figure 1 by the thick black dot, are right on the outside edge of the cloud of points. Additionally, the relative capital-TFP ratio of 0.087 implied by the state variables' initial stocks is almost identical to the one of Senegal $\left(\frac{2.36}{26.96}=0.088\right)$, and higher than for example the ones of Bangladesh $\left(\frac{2.55}{48.71}=0.052\right)$ and Mozambique $\left(\frac{0.57}{25.66}=0.022\right)$. We then conclude that our initial values do seem to belong to the developing world.

\subsubsection{Technology Transfer versus Capital Accumulation}

Alwyn Young $(1994,1995 a)$ shows that East Asian countries grew mostly from capital accumulation, and that their TFP growth rates were not extraordinary high. As Klenow and Rodríguez-Clare (1997) argue, because of this work "many people has concluded that the East Asian episodes illustrate the importance of neoclassical transitional dynamics rather than technological catch-up." Some authors, like Barro and Sala-i-Martin (1995) argue that Young's interpretation of his results is not correct because growth in capital accumulation induced by rising TFP should be causally attributed to technology. The predictions of the R\&D-based growth model transitional dynamics confirm Barro and Sala-i-Martin's intuition.

Figure 2 depicts the time paths for per capita output, per capita output growth, and the contributions of physical capital accumulation and TFP. Output is expressed as a fraction of its steady state value. In all cases, starting from a relative output level of 19 percent, the half life is reached in between 17 and 18 years, and 80 percent of the transition is completed in 32 years. Output growth in the first few periods rises with the intertemporal elasticity of substitution, and declines latter on, generating a less linear convergence path. At impact, the growth rate of output is roughly 27 percent for $\sigma=1$, and 21 percent for $\sigma=2$. Although slightly, the rate also decreases with $\lambda$. The reason is that stronger diminishing returns to R\&D have to be accompanied by a larger $\rho$ to replicate the Japanese convergence path. A bigger advantage of "backwardness" in turn makes optimal higher growth rates at early stages of development.

\footnotetext{
${ }^{11}$ We do not prove formally that the stable adjustment path is unique. Eicher and Turnovsky (1997), however, establish sufficient conditions for this to be so in a very similar non-scale growth model. In terms of our parameters, those conditions are equivalent to requiring that $\phi+\lambda \xi<1$ and $\alpha<\frac{1}{2}$. It turns out that our calibrated parameters fulfil these restrictions. Furthermore, during the innumerable simulations, we always found the same stable arm, independent of the initial guess used to approximate the decision rules, and the initial values of the state values.
} 
The decomposition of the growth rate of per capita output into its two components gives the following results. Accumulation of capital accounts for more than 90 percent at impact when $\sigma=1$, and more than 70 percent when $\sigma=1$. Moreover, in both cases, the cumulative capital accumulation contribution over the first 20 periods is larger than 65 percent, and larger than 55 percent even after 50 periods. At the steady state, however, it goes down to 36 percent, which is the capital input weight. The contribution of the Solow residual, on the other hand, increases over time. The effects of changes in $\sigma$ and $\lambda$ are the same as before. More consumption smoothing implies more linear paths for the growth components, whereas stronger diminishing returns to $\mathrm{R} \& \mathrm{D}$ raise the role of technology transfer. The big contribution of capital accumulation along the transition is clearly due both to the relatively low initial level of capital and the incidence of technical change on input growth - the initial relative level of capital declines from 12 percent to 4.9 percent because of the technological gap. These results can explain Young's $(1994,1995 \mathrm{a})$ finding that capital accumulation has been the main contributor to the East Asian countries' rapid growth experiences. But this occurs even though TFP is a more important contributor to the economic development process. Notice that without technology transfer, Japanese per capita output could have reached at most 40.8 percent of the U.S. level, but without non-TFP-induced capital accumulation, it would have achieved 46.6 percent.

\subsubsection{The Speed of Convergence Without Imitation}

In his seminal contribution, Jones (1995a) linearizes the non-scale R\&D-based growth framework around the steady state, and finds half lives of per capita output in the hundred of years. Williams (1995) confirms this result using numerical methods, but for shocks to the state variables of just 10 percent. Eicher and Turnovsky (1997), however, find that non-scale growth models can display variable speed of convergence. Faster adjustment paths might then occur for bigger shocks. Next, we show that without imitation the model cannot reproduce the Japanese output data.

In order to see this, we do experiments for $\rho$ equal to 0.05 . When the value of $\rho$ is that small, the effect of imitation is negligible. Figure 3 shows that now it takes output more than 50 years to achieve the 74 percent level, instead of the 30 years implied by the Japanese output data. When $\lambda$ is 0.75 and $\sigma$ is 1 , the model accomplishes its smallest half life of convergence, 39 years. The adjustment speed decreases as the diminishing returns to $R \& D$ get stronger, and as the inverse of the intertemporal elasticity of substitution rises. For example, the half life becomes 60 years for $(\lambda, \sigma)=(0.5,1)$, reaching 149 years when $(\lambda, \sigma)=(0.25,2)$. We then conclude that the introduction of imitation in the non-scale growth model is the key to account for growth miracles.

\subsubsection{The R\&D Model versus the Solow Model}

We turn now to compare the R\&D-based growth model's predictions to the Solow framework's. As we said in the introduction, King and Rebelo (1993) show that the 
predictions of the Solow model transitional dynamics are counterfactual either with respect to the sequence of interest rates or the consumption shares. They find that "in order for the Japanese convergence toward the U.S. income level in the postwar era to be the result of transitional dynamics, the Japanese real annual interest rate would have been over 500 percent in 1950." Figure 4 plots Japanese interest rates for the period 1955 to 1988 as computed by Christiano (1989). Looking at these estimates, which are always below 80 percent, a 500 percent interest rate seems to be implausibly high.

Increasing the capital share in the neoclassical growth model to consider human as well as physical capital can decrease substantially the MPK, and therefore the interest rate. Specifically, using a logarithmic utility function, they find that the interest rate decreases to roughly 30 percent at early stages of development when the capital input weight is 0.5 . For this value of the capital share, however, the consumption share reaches values below 50 percent when levels of output are just 50 percent below trend. ${ }^{12}$ This occurs because the higher the capital input weight, the weaker the Solow model's convergence engine; thus raising the investment share necessary to achieve a given rate of growth. In the Solow model, the consumption share becomes roughly 32 percent in both the long and the short runs when the capital input weight is 0.9. Table 4 shows the largest investment share and the smallest consumption share during the period 1960-85 for the fastest-converging economies, and the average values over the interval 1980-90 for the most developed OECD countries, which must be very close to the steady state. ${ }^{13}$ We can see that most of the rapidly converging economies display consumption shares above 50 percent. For instance, Hong Kong and Korea have converged at an average 4.6 and 4.5 percent, respectively, enjoying consumption shares above 62 percent. If we take into account the Mankiw, Romer and Weil's (1992, page 417) estimate that a reasonable value for the extended capital share is at least 66 percent, it becomes clear that the Solow model cannot account for most rapid growth experiences.

The shares of the different expenditure categories and the interest rate paths predicted by the $\mathrm{R} \& \mathrm{D}$ model are depicted in Figure 5 . We can see that the $\mathrm{R} \& \mathrm{D}$ model is able to overcome the counterfactual implications of the neoclassical growth framework. For a level of output of 19 percent below trend, the real interest rate is never bigger than 42 percent for $\sigma=1$, and 56 percent for $\sigma=2$. These are much lower values than the 500 obtained by King and Rebelo (1993) using roughly the same parameter values as us, and seem reasonable looking at Figure 4. To understand this result, recall that the interest rate is pinned down by the MPK, equation (8). Since we have an initial stock of capital that is higher than in King and Rebelo, the initial MPK is lower. Additionally, at impact, the R\&D model shifts the MPK function down because the Solow residual is smaller than its steady state value; pushing the interest rate down even more. The interest rate is higher when $\sigma$ equals 2 because

\footnotetext{
${ }^{12}$ See King and Rebelo (1993, Figure 5).

${ }^{13}$ The data comes from the PWT, Mark 5.6, web site http://www.nber.org/pwt56.html. The countries listed in Table 4 as fastest-converging are those from the non-oil sample with the highest average relative-income growth rates over the period 1960 to 1985 . To obtain the extreme values, the series were slightly smoothed using 3 -year moving averages.
} 
more consumption smoothing generates lower physical capital investment and R\&D shares. Since for $\sigma=2$ present and future consumption are complementary, the interest rate must then rise to reduce the saving rate and clear the financial market. Finally, the interest rate adjustment path is downward slopping as in the Solow model. The reason is that the capital stock grows much faster than the level of technology, making the MPK decrease over time.

With respect to the consumption shares, these are only below 50 percent for the non-strong diminishing returns to R\&D cases, when $\sigma=1$, and only during the first few periods. For the low elasticity of substitution case, for example, consumption shares are never below 65 percent. The key is the large average imitation productivity at early stages of development, which reduces the initial $R \& D$ and capital investments required to generate high growth rates. In all cases, the $R \& D$ share actually starts at values below its steady state level.

It is important to mention that physical capital investment shares are also quite reasonable. Except for the weak diminishing returns to R\&D cases, when $\sigma=1$, and only during the first few periods, investment is always below 42 percent, which is roughly the higher value in Table 4 . The model also does well at steady state predictions. OECD countries' shares in Table 4 range from 46.8 to 67.2 percent for consumption, and from 17.1 to 33.8 for investment. Except for the $(\lambda, \sigma)=$ $\{(0.25,2),(0.5,2)\}$ cases, we see that the $\mathrm{R} \& \mathrm{D}$ model predicts steady state values that are contained in those intervals.

\section{$5 \quad$ Summary and Conclusions}

Recent literature has compared the predictions of non-scale R\&D-based growth models to the ones of alternative growth theories. Bernard and Jones (1996a, 1996b) provide empirical evidence about the importance of technology in understanding differences in income levels and output growth rates across countries. Jones (1995a, 1995b) finds growth models that imply scale effects inconsistent with observation. Barro and Sala-i-Martin (1995, Chapter 7) show that the cross-country growth regression results supporting the neoclassical growth framework cannot be used to discriminate against R\&D-based growth models. Finally, Eicher and Turnovsky (1997) find that, unlike the neoclassical and the two-sector endogenous growth models, nonscale growth frameworks can generate variable speeds of convergence both through time and across different sectors of the economy. They also show that non-scale growth models deliver asymptotic speeds of adjustment consistent with the empirical evidence.

Our work contributes to this literature. We have shown that the transitional dynamics of the non-scale R\&D-based growth model outperform the neoclassical growth framework in explaining cross country differences in rates of economic development. Our experiments imply that most couples $(\sigma, \lambda)$ in which the intertemporal elasticity of substitution and the degree of diminishing returns to $R \& D$ take on values between 1 and 2 and between 0.5 and 0.75 , respectively, deliver predictions that are consistent with observation. The key is the introduction of technology imitation. 
This provides an additional growth engine that allows for rapid convergence along with interest rates and consumption and physical capital investment shares that are plausible according to cross-country data.

Furthermore, after analyzing the transitional dynamics of the R\&D model, it is clear that a big contribution of capital accumulation to economic growth along most of the development path is what we should expect. But our analysis also implies that without technology transfer important differences in income levels across countries are condemned to persist.

It would be interesting to compare the model's predictions about innovation and imitation investment to the data. The problem is that, as far as we know, good data about imitation and innovation investments do not exist. Imitation expenditures are not always considered as R\&D. For example, in agriculture, public support to imitation is usually referred as "extension services", and is not included in R\&D figures. The construction of such a data set is clearly outside the scope of this paper.

We leave to future research the introduction of human capital accumulation into the model. Studying the dynamics of this framework would allow us to further explore its capacity to explain cross country differences in levels and rates of economic development using new data sets, like schooling figures. 


\section{References}

[1] Aghion, P. and P. Howitt, 1992, A Model of Growth Through Creative Destruction, Econometrica 60, 323-351.

[2] Attanasio, O. and G. Weber, 1993, Consumption, The Interest Rate and Aggregation, Review of Economic Studies 60, 631-49.

[3] Backus, D., P. Kehoe and T. Kehoe, 1992, In Search of Scale Effects in Trade and Growth, Journal of Economic Theory, 377-409.

[4] Barro, R. J., N. Mankiw and X. Sala-i-Martin, 1995, Capital Mobility in Neoclassical Models of Growth, American Economic Review 85, 103-115.

[5] Barro, R. J. and X. Sala-i-Martin, 1992. Convergence, Journal of Political Economy $100,223-251$.

[6] Barro, R. J. and X. Sala-i-Martin, 1995, Economic Growth (McGraw-Hill), Chapter 8.

[7] Barro, R. J. and X. Sala-i-Martin, 1997, Technological Diffusion, Convergence and Growth, Journal of Economic Growth 2, 1-26.

[8] Benhabid, J., R. Perli and D. Xie, 1994, Monopolistic Competition, Indeterminacy and Growth, Ricerche Economiche 48, 279-298.

[9] Bernard, A. B. and C. I. Jones,1996a, Comparing Apples to Oranges: Productivity, Convergence and Measurement Across Industries and Countries, American Economic Review 86, 1216-1238, .

[10] Bernard, A. B. and C. I. Jones, 1996b, Productivity Across Industries and Countries: Time Series Theory and Evidence, Review of Economics and Statistics, $135-146$.

[11] Bureau of Labor Statistics, August 1991, Multifactor Productivity Measures 1990 (U.S. Department of Labor), News.

[12] Christiano, L. J, 1989, Understanding Japan's Savings rate: The Reconstruction Hypothesis, Federal Reserve Bank of Minneapolis Quarterly Review 13, 10-25.

[13] Dinopoulos, E. and P. Thompson, 1995, Is Endogenous Growth Empirically Relevant, University of Florida Working Paper No. 95-96-8.

[14] Dinopoulos, E. and P. Thompson, 1996, A Contribution to the Empirics of Endogenous Growth, Eastern Economic Journal 22, 389-400.

[15] Eaton, J. and S. Kortum, 1995, Trade in Ideas: Patenting and Productivity in the OECD, NBER Working Paper No. 5049. 
[16] Eicher, T. and S. J. Turnovsky, 1997, Convergence Speeds and Transitional Dynamics in Non-Scale Growth Models, mimeo, University of Washington.

[17] Freeman, C., 1988, Japan: A New National System of Innovation, in Dosi et al., eds., Technical Change and Economic theory (Pinter Publishers).

[18] García-Castrillo, P., and M. Sanso, 1997, Optimal Industrial Policy in a Model of Technological Change with Capital Goods, mimeo, Universidad de Zaragoza.

[19] Gerschenkron, Alexander, 1952, Economic Backwardness in Historical Perspective, in Bert F. Hoselitz, ed., The progress of Underdeveloped Areas (University of Chicago Press, Chicago, IL).

[20] Gomes, J., 1994, Transition Dynamics in an Economy with Endogenous Technological Change, mimeo, University of Rochester.

[21] Grossman, G. M. and E. Helpman, 1991, Innovation and Growth in the Global Economy (MIT Press, Cambridge, MA).

[22] Hall, R. E., 1988, Intertemporal Substitution in Consumption, Journal of political Economy 96, 339-57.

[23] Jones, C. I., 1995a, R\&D-Based Models of Economic Growth, Journal of Political Economy 103, 759-84.

[24] Jones, C. I., 1995b, Time Series Tests of Endogenous Growth Models, Quarterly Journal of Economics 110, 495-525.

[25] Jones, C. I., 1996, Convergence Revisited, mimeo, Stanford University.

[26] Jones, C. I. and J. C. Williams, 1996, Too Much of a Good Thing? The Economics of Investment in R\&D, mimeo, Stanford University.

[27] Judd, K. L., 1992, Projections Methods for Solving Aggregate Growth Models, Journal of Economic Theory 58, 410-452.

[28] Judd, M.A., J.K. Boyce and R.E. Evenson, 1986, Investing in Agricultural Supply: The Determinants of Agricultural Research and Extension Investment, Economic Development and Cultural Change 36, 77-113.

[29] King, R. G. and S. T. Rebelo, 1993, Transitional Dynamics and Economic Growth in the Neoclassical Model, American Economic Review 83, 908-931.

[30] Klenow, P. J. and A. Rodríguez-Clare, 1997, Economic Growth: A Review Essay, Journal of Monetary Economics 40.

[31] Kocherlakota, N. R. and K. Yi, 1996, A Simple Time Series Test of Endogenous vs. Exogenous Growth Models: An Application to the United States, Review of Economics and Statistics 78, 126-134. 
[32] Kocherlakota, N. R. and K. Yi, 1997, Is There Endogenous Long Run Growth? Evidence from the U.S. and the U.K., Journal of Money, Credit and Banking $29,235-262$.

[33] Kortum, S., 1992, Inventions, R\&D and Industry Growth, mimeo, Boston University.

[34] Lucas, R. E., 1988, On the Mechanics of Economic Development, Journal of Monetary Economics 22, 3-42.

[35] Mankiw, N. G., D. Romer and D. N. Weil, 1992, A Contribution to the Empirics of Economic Growth, Quarterly Journal of Economics 107, 407-437.

[36] Mansfield, E., M. Schwartz and S. Wagner, 1981, Imitation Costs and Patents: An Empirical Study, Economic Journal 91, 907-918.

[37] Papageorgiou, C., 1996, Do Technology Transfers Matter in Economic Development?, mimeo, University of Pittsburgh.

[38] Parente, S.L. and E.C. Prescott, 1994, Barriers to Technology Adoption and Development, Journal of Political Economy 102, 298-321.

[39] Pray, C. E. and V. W. Ruttan, 1990, Science and Technology Policy: Lessons from the Agricultural Sector in South and Southeast Asia, in Science and Technology: Lessons for Development Policy (Westview Press), R. E. Evenson and G. Ranis, Eds.

[40] Romer, P. M., 1990, Endogenous Technical Change, Journal of Political Economy 98, S71-S102.

[41] Romer, P. M., 1992, Two Strategies for Economic Development: Using Ideas and Producing Ideas, World Bank Research Observer: supplement, 63-115.

[42] Romer, P. M., 1993, Idea Gaps and Object Gaps in Economic Development, Journal of Monetary Economics 32, 543-573.

[43] Segerstrom, P. S., 1995, Endogenous Growth Without Scale Effects, mimeo, Michigan State University.

[44] Williams, J. C., 1994, Patent Protection, Taxation, and The supply and Demand for R\&D, mimeo, Stanford University.

[45] Williams, J. C., 1995, Taking Growth Seriously: Theory and Measurement in an R\&D-Based Growth Model, mimeo, Stanford University.

[46] Young, A., 1992, A Tale of Two Cities: Factor Accumulation and Technical Change in Hong Kong and Singapore, NBER Macroeconomics Annual, 13-54.

[47] Young, A., 1994, Lessons from the East Asian NICs: A Contrarian View, European Economic Review 38, 964-73. 
[48] Young, A., 1995a, The Tyranny of Numbers: Confronting the Statistical Realities of the East Asian Growth Experience, Quarterly Journal of Economics 110, 641-680.

[49] Young, A., 1995b, Growth Without Scale Effects, NBER Working Paper No. 5211. 


\section{A The Steady State Growth Rate of Output}

We first prove that along the balanced growth path $g_{A}=g_{A_{w}}$. To see that $g_{A}$ cannot be larger than $g_{A_{w}}$, notice that $A_{t}$ would then be eventually bigger than $A_{w t}$. The definition of the international knowledge pool, however, requires that $A_{w t}$ must always be greater or equal than $A_{t}$.

Showing that $g_{A}$ smaller than $g_{A_{w}}$ is not compatible with the steady state needs a little bit more of algebra. From equations (7), (10) and (12), we get that, at steady state,

$$
S_{R, t+1}=\frac{\lambda \xi g_{A}}{\left(1+r_{s s}\right) \frac{G_{A}}{G_{R}}-1-g_{A}\left(\phi-\rho \lambda \frac{T_{t+1}^{\frac{\rho \lambda}{1+\lambda}}}{1+T_{t+1}^{\frac{\rho \lambda}{1-\lambda}}}\right)} .
$$

Noting that, along the balanced growth path, $T_{t+1}=\left(\frac{G_{A_{w}}}{G_{A}}\right) T_{t}$, we can write

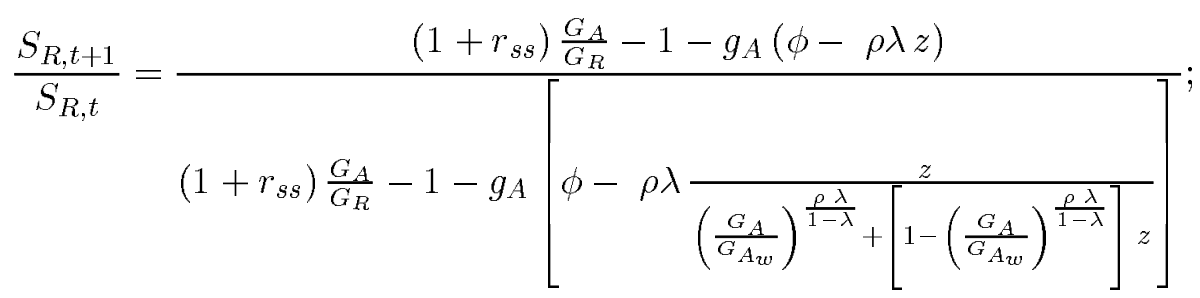

where $z=\frac{\frac{\rho \lambda}{T_{t}^{1-\lambda}}}{1+T_{t}^{\frac{\rho \lambda}{1-\lambda}}}$. At steady state, $G_{Y}$ and $G_{R}$ must be constant. This implies

$$
\frac{d\left(\frac{S_{R, t+1}}{S_{R, t}}\right)}{d z}=\frac{d\left(\frac{G_{R}}{G_{Y}}\right)}{d z}=0 .
$$

Next, we prove that when $g_{A}$ is less than $g_{A_{w}}$ this derivative is positive, and no steady state can then exist.

Differentiating (21) with respect to $z$ and rearranging, we find that the sign of the derivative is the sign of the following expression:

$$
\left[\left(1+r_{s s}\right) \frac{G_{A}}{G_{R}}-1-\phi g_{A}\right] a+\left(\rho \lambda g_{A} z\right) b
$$

where

$$
a=1-\frac{\left(\frac{G_{A}}{G_{A_{w}}}\right)^{\frac{\rho \lambda}{1-\lambda}}}{\left\{\left(\frac{G_{A}}{G_{A_{w}}}\right)^{\frac{\rho \lambda}{1-\lambda}}+\left[1-\left(\frac{G_{A}}{G_{A_{w}}}\right)^{\frac{\rho \lambda}{1-\lambda}}\right] z\right\}^{2}} ;
$$

and

$$
b=\frac{z\left[1-\left(\frac{G_{A}}{G_{A_{w}}}\right)^{\frac{\rho \lambda}{1-\lambda}}\right]}{\left\{\left(\frac{G_{A}}{G_{A_{w}}}\right)^{\frac{\rho \lambda}{1-\lambda}}+\left[1-\left(\frac{G_{A}}{G_{A_{w}}}\right)^{\frac{\rho \lambda}{1-\lambda}}\right] z\right\}^{2}} .
$$


When $g_{A}$ is less than $g_{A_{w}}, T_{t}$ goes to infinity with $t$. Therefore, the variable $z$ goes to one along the balanced growth path. This says, in turn, that a goes to $\left[1-\left(\frac{G_{A}}{G_{A_{w}}}\right)^{\frac{\rho \lambda}{1-\lambda}}\right]>0$, and that $b$ eventually becomes larger than $a$. Economic sense requires that $0 \leq S_{R t} \leq 1$. From equation (20), we then have that

$$
\left[\left(1+r_{s s}\right) \frac{G_{A}}{G_{R}}-1-\phi g_{A}+\rho \lambda g_{A} z\right]>0 .
$$

The above arguments imply that expression (22) becomes eventually positive along the balanced growth path. The only scenario compatible with a steady state in which all variables grow at constant rates is then one in which $g_{A}$ equals $g_{A_{w}}$.

We turn now to calculating the steady state growth rate of output. From equation (1), we get that

$$
G_{Y}=G_{A}^{\xi}(1+n)^{\alpha} G_{K}^{1-\alpha} .
$$

Using the usual argument about the constancy of the capital-output ratio (i.e., $G_{K}=$ $G_{Y}$ ), we can rewrite the balanced growth rate of output as

$$
G_{Y}=G_{A}^{\frac{\xi}{\alpha}}(1+n) .
$$

From (10), we deduce that along the balanced growth path

$$
G_{A}=\mu A_{t}^{\phi-1} R_{t}^{\lambda}\left(1+T_{t}^{\frac{\rho \lambda}{1-\lambda}}\right)^{1-\lambda}+1 .
$$

Given that $T_{t}$ remains constant at steady state, it must therefore be the case that

$$
G_{A}^{1-\phi}=G_{R}^{\lambda}
$$

Solving for $G_{A}$ in (24), then substituting the resulting expression into (23), and finally noting that $G_{R}=G_{Y}$, we get that the balanced growth rate of output equals

$$
G_{Y}=(1+n)^{\frac{1-\phi}{1-\phi-\lambda \frac{\xi}{\alpha}}} .
$$

Because in our model the balanced growth rate of TFP equals $G_{A}^{\xi}$, expression (24) also implies that

$$
G_{T F P}=G_{R}^{\frac{\lambda \xi}{1-\phi}} .
$$

Taking now logs in (25), we get the expression used to estimate the parameter $\phi$,

$$
\phi=1-\lambda \xi \frac{\log \left(1+g_{R}\right)}{\log \left(1+g_{T F P}\right)} .
$$




\section{B The Decentralized Economy Behind the Parameters}

Consider an economy in which there are two types of firms: consumption goods producers, and intermediate goods manufacturers. The latter also invest resources to learn new designs for new types of producer durables. The final goods sector is made up of a large number of identical firms. Let $x_{t i}$ be the amount of intermediate good $i$ allocated to production at time $t$. The constant returns technology for producing consumption goods is given by

$$
Y_{t}=L_{t}^{\alpha}\left[\int_{0}^{A_{t}} x_{t i}^{(1-\alpha) \gamma} d i\right]^{\frac{1}{\gamma}}, 0<\alpha<1, \gamma>0 .
$$

If $\gamma<1$, intermediate goods are complementary; they are substitutes if $\gamma>1$. Final goods manufacturers are price takers, and earn zero profits in equilibrium. They solve the following problem:

$$
\max _{\left\{L_{t}, x_{t i}\right\}}\left\{L_{t}^{\alpha}\left[\int_{0}^{A_{t}} x_{t i}^{(1-\alpha) \gamma} d i\right]^{\frac{1}{\gamma}}-\omega_{t} L_{t}-\int_{0}^{A_{t}} p_{t i} x_{t i} d i\right\}
$$

where $p_{t i}$ is the rental price of producer durable $i$ at date $t$; and $\omega_{t}$ is the wage rate in period $t$. For the interior solution to this problem, the first order condition with respect to $x_{t i}$ is

$$
p_{t i}=\left(\frac{1-\alpha}{1-\tau_{x t i}}\right) \frac{Y_{t}}{A_{t} x_{t i}}, i \in\left(0, A_{t}\right) .
$$

Equation (27) is the inverse demand function for producer durable $i$ at date $t$. Given that all intermediate goods designs provide the same improvement in productivity, we can focus on the symmetric equilibrium in which capital is evenly distributed over all available types; that is, $x_{t i}=\bar{x}_{t}$ for all $i$. The country's stock of physical capital at date $t\left(K_{t}\right)$ then equals $A_{t} \bar{x}_{t}$, and the production technology takes the following standard Cobb-Douglas form:

$$
Y_{t}=A_{t}^{\xi} L_{t}^{\alpha} K_{t}^{1-\alpha}, \quad \xi=\frac{1}{\gamma}-(1-\alpha)
$$

Intermediate goods manufacturers borrow capital, which is allocated to producing existing varieties of producer durables and to learning new varieties. We make the following four simplifying assumptions: (i) producer durables are rented rather sold; (ii) there exist perfectly competitive markets for patents and physical capital; (iii) intermediate goods producers take as given the present value of designs; and (iv) one unit of raw capital can be costlessly converted into one unit of any type of producer durable. Notice then that the price of one unit of physical capital and the price of a patent right will equal one unit of output and the present value of the design, respectively. At date $t$, firms therefore decide the amount of producer durable $i$ that will be available in period $t+1$ by solving the following two-period problem: 


$$
\max _{\left\{x_{t+1, i}\right\}}\left\{-\bar{V}_{t}-x_{t+1, i}+\left(\frac{1}{1+r_{t+1}}\right)\left[p_{t+1, i} x_{t+1, i}+(1-\delta) x_{t+1, i}+\bar{V}_{t+1}\right]\right\}, i \in\left(0, A_{t}\right]
$$

where $\bar{V}_{t}$ is the patent rights' present value at date $t$ - notice that all designs are alike in productivity terms, regardless of whether they are copied or created from scratch.

Monopoly pricing of intermediate goods implies that $p_{t i}$ is given by the final goods manufacturers' inverse demand function, equation (27). Substituting (27) back into (28), solving the problem, and recalling that in the symmetric equilibrium $x_{t i}$ equals $\bar{x}_{t}$ for all $i$, we get that if the number of firms is large,

$$
p_{t i}=\frac{r_{t}+\delta}{\gamma(1-\alpha)}=\bar{p}_{t}, \text { for all } i
$$

that is, the price is proportional to the constant elasticity of substitution between intermediate goods. If we denote the mark-up ratio by $m$, equation (29) says that

$$
m=\frac{1}{\gamma(1-\alpha)}
$$

Remember that we found that $\xi$ equals $\frac{1}{\gamma}-(1-\alpha)$. Expression (30), therefore implies that we can write the elasticity of output with respect to the technological level as

$$
\xi=(m-1)(1-\alpha) .
$$

Our next task is to show that the steady state value of the relative international pool of designs $\left(T_{s s}\right)$ equals the ratio of imitation to innovation public support. Assume that, in the economy, there exists a Government (or central planner) that collects lump-sum taxes, and uses the revenues to tax/subsidize the R\&D activities. Knowing the gains from learning new designs, intermediate goods producers choose how much capital to invest in imitation and innovation. Free entry in the producer durables sector implies that, at each instant in time, the amount invested in R\&D must equal the present value of the learned ideas. We will have then two zero-profit equilibrium conditions, one for innovation and another for imitation. From the R\&D technology, equation (2), they can be stated formally as follows:

$$
R_{I t}^{c e}\left(1-\tau_{I t}\right)=\bar{V}_{t} \mu A_{t}^{\phi} R_{I t}^{\lambda}
$$

and

$$
R_{C t}^{c e}\left(1-\tau_{C t}\right)=\bar{V}_{t} \mu A_{t}^{\phi}\left[R_{C t}\left(\frac{\eta A_{w t}}{A_{t}}\right)^{\rho}\right]^{\lambda} ;
$$

where ce denotes optimal allocations in the competitive equilibrium with taxes; and $\tau_{I t}$ and $\tau_{C t}$ are the rates at which the government subsidizes investment in innovation and imitation, respectively. The LHS of expressions (31) and (32) represents the cost incurred in each of the R\&D activities, whereas the RHS gives the benefit. 
Combining zero profit conditions (31) and (32), we obtain the optimal ratio of imitation to innovation investment:

$$
\frac{R_{C t}^{c e}}{R_{I t}^{c e}}=\left[\left(\frac{1-\tau_{I t}}{1-\tau_{C t}}\right)\left(\frac{\eta A_{w t}}{A_{t}}\right)^{\rho \lambda}\right]^{\frac{1}{1-\lambda}} .
$$

Conditions (9) and (33) imply that

$$
\frac{R_{C t}^{c e}}{R_{I t}^{c e}}\left(\frac{1-\tau_{C t}}{1-\tau_{I t}}\right)^{\frac{1}{1-\lambda}}=\frac{R_{C t}^{s o}}{R_{I t}^{s o}} ;
$$

where so denotes social optimum allocations.

The central planner will choose $\tau_{I t}$ and $\tau_{C t}$ so as to equalize $R_{I t}^{c e}$ to $R_{I t}^{s o}$, and $R_{C t}^{c e}$ to $R_{C t}^{s o}$. Hence, from (34), imitation and innovation will be subsidized at the same rate; that is, $\tau_{C t}=\tau_{I t}=\bar{\tau}_{t}$ for all $t$. Equation (9) then implies that the ratio of imitation to innovation public support equals the value of the relative international pool of designs; that is,

$$
\frac{R_{C 2}^{s o} \bar{\tau}_{t}}{R_{I 2}^{s o} \bar{\tau}_{t}}=\left(\frac{\eta A_{w t}}{A_{t}}\right)^{\frac{\rho \lambda}{1-\lambda}}=T_{t} .
$$

This equality will hold, in particular, at the steady state. 
Table 1: Solution Algorithm Accuracy for Analyzed Cases

\begin{tabular}{|c|c|l|ll|cl|}
\hline & & & \multicolumn{2}{|c|}{ \% of Error for $\hat{C}_{t+1}$} & \multicolumn{2}{c|}{ \% of Error for $\hat{R}_{t+1}$} \\
\hline Case & $\sigma$ & $\lambda$ & Average & Maximum & Average & Maximum \\
\hline 1 & 1 & 0.25 & 0.08 & 0.35 & 0.10 & 0.50 \\
2 & 1 & 0.5 & 0.08 & 0.35 & 0.15 & 0.72 \\
3 & 1 & 0.75 & 0.08 & 0.35 & 0.34 & 1.59 \\
\hline 4 & 2 & 0.25 & 0.06 & 0.31 & 0.16 & 0.88 \\
5 & 2 & 0.5 & 0.06 & 0.31 & 0.24 & 1.31 \\
6 & 2 & 0.75 & 0.07 & 0.33 & 0.75 & 3.40 \\
\hline
\end{tabular}

Table 2: Parameter Values Used in the Simulations

\begin{tabular}{|c|c|c|c|c|c|c|}
\hline \multirow{2}{*}{\multicolumn{2}{|c|}{$\begin{array}{c}\text { Constant } \\
\text { Parameters' values }\end{array}$}} & \multicolumn{5}{|c|}{ Changing Parameters' values } \\
\hline & & \multirow{2}{*}{$\frac{\text { Case }}{1}$} & \multirow[t]{2}{*}{$\sigma$} & \multirow{2}{*}{$\frac{\lambda}{0.25}$} & \multirow{2}{*}{$\begin{array}{c}\text { Implied } \phi \\
0.92 \\
\end{array}$} & \multirow{2}{*}{$\begin{array}{c}\text { Calibrated } \rho \\
2.03\end{array}$} \\
\hline$\alpha$ & 0.64 & & & & & \\
\hline $\bar{\beta}$ & 0.96 & 2 & 1 & 0.5 & 0.84 & 0.83 \\
\hline$\delta$ & 0.1 & 3 & 1 & 0.75 & 0.76 & 0.42 \\
\hline$n$ & 0.014 & 4 & 2 & 0.25 & 0.92 & 2.3 \\
\hline$\xi$ & 0.126 & 5 & 2 & 0.5 & 0.84 & 1.03 \\
\hline$T^{*}$ & 0.41 & 6 & 2 & 0.75 & 0.76 & 0.58 \\
\hline
\end{tabular}

Table 3: Research and Extension Expenditures as Percentage of the Value of Agricultural Product: Public Sector

\begin{tabular}{|l|cc|cc|cc|}
\hline & \multicolumn{2}{|c|}{ Research $(R)$} & \multicolumn{2}{c|}{ Extension $(I)$} & \multicolumn{2}{c|}{$I / R$} \\
\hline Country Group $^{*}$ & 1970 & 1980 & 1970 & 1980 & 1970 & 1980 \\
\hline Low-income & 0.27 & 0.5 & 0.43 & 0.44 & 1.59 & 0.88 \\
Middle-income & 0.57 & 0.81 & 1.01 & 0.92 & 1.77 & 1.14 \\
Semi-ind'zed & 0.54 & 0.73 & 0.51 & 0.59 & 0.94 & 0.81 \\
Industrialized & 1.37 & 1.5 & 0.57 & 0.62 & 0.41 & 0.41 \\
\hline
\end{tabular}

Source: Judd, Boyce and Evenson (1986)

* The country groups were formed according to the World Bank Development Report

1980 (World Bank, Washington, D.C.) as follows: (1) Industrialized countries - members of the OECD, except for Greece, Portugal, Spain, and Turkey; (2) Semi-industrialized countries - other countries with annual per capita income above 1,050; (3) Middle-income developing - other nations with annual per capita income between $\$ 360$ and $\$ 1,050$; and

(4) Low-income developing - other countries with annual per capita income below $\$ 360$. Eastern Europe, Soviet Union and China were excluded from the sample. 
Table 4: Consumption and Investment Shares, Selected Countries

\begin{tabular}{|l|cc||l|c|cc|}
\hline & \multicolumn{2}{|c|}{$1980-90$} & & $1960-85$ & \multicolumn{2}{c|}{$1960-85$} \\
\hline Country & $\begin{array}{c}\text { Av. C } \\
\text { share }\end{array}$ & $\begin{array}{c}\text { Av. I } \\
\text { share }\end{array}$ & Country & $\begin{array}{c}\text { Av. } \\
\text { growth }\end{array}$ & $\begin{array}{c}\text { Min C } \\
\text { share }\end{array}$ & $\begin{array}{l}\text { Max I } \\
\text { share }\end{array}$ \\
\hline Japan & 56.6 & 33.8 & Singapore & 4.9 & 53.2 & 41.1 \\
Finland & 52.8 & 32.0 & Hong kong & 4.6 & 69.1 & 24.5 \\
Switzerland & 61.7 & 30.6 & Rep. Korea & 4.5 & 62.1 & 31.0 \\
Norway & 46.8 & 27.6 & Botswana & 4.2 & 44.7 & 36.8 \\
Australia & 63.0 & 26.9 & Romania & 4.1 & 69.6 & 36.3 \\
\hline Luxembourg & 63.3 & 26.7 & Taiwan & 4.0 & 55.6 & 28.6 \\
Canada & 61.4 & 25.3 & Reunion & 3.9 & 51.2 & 33.0 \\
France & 60.4 & 25.2 & Japan & 3.5 & 56.0 & 39.3 \\
Iceland & 59.4 & 24.9 & Syria & 3.3 & 63.4 & 18.8 \\
Austria & 61.7 & 24.7 & Cyprus & 3.1 & 54.1 & 31.6 \\
\hline W. Germany & 58.6 & 24.5 & Malta & 3.1 & 63.4 & 32.3 \\
Italy & 64.6 & 24.4 & Jordan & 3.1 & 69.4 & 22.2 \\
New Zealand & 63.6 & 24.1 & Gabon & 3.0 & 27.8 & 41.8 \\
Denmark & 55.7 & 21.5 & Greece & 2.5 & 64.1 & 32.4 \\
Sweden & 55.7 & 21.2 & U.S.S.R. & 2.4 & 45.5 & 40.2 \\
\hline Netherlands & 63.4 & 21.0 & Indonesia & 2.4 & 57.6 & 26.3 \\
U.S.A. & 67.2 & 21.0 & Congo & 2.3 & 49.1 & 17.7 \\
Belgium & 67.2 & 20.7 & Malaysia & 2.2 & 51.9 & 32.2 \\
U.K. & 65.0 & 17.1 & Yugoslavia & 2.2 & 44.9 & 31.8 \\
\hline
\end{tabular}


Figure 1: Relative Levels of Technology and Physical Capital per Capita in 1990, Selected Countries (U.S.A. $=100)$. Source: Jones (1996, Appendix Table). Countries are identified by the PWT 3-character codes.

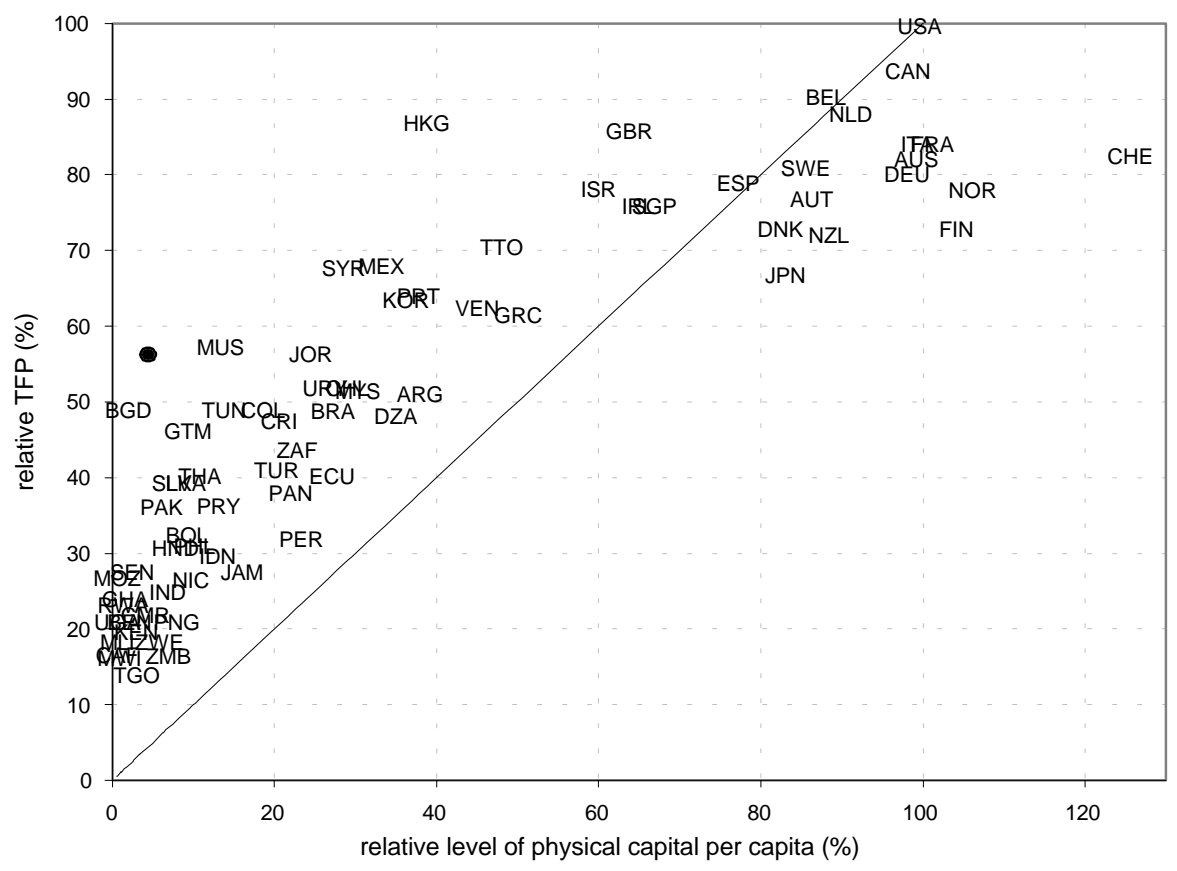




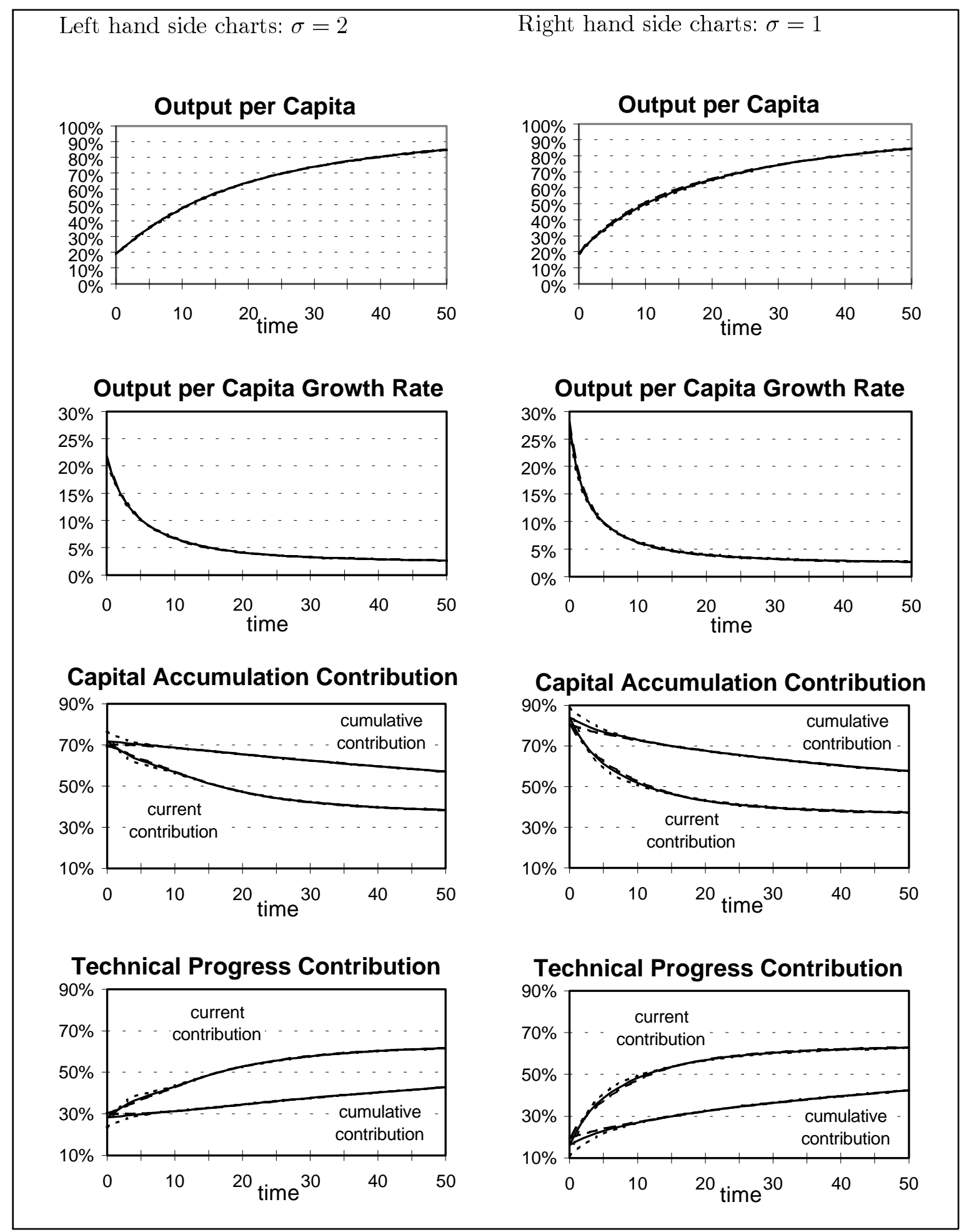

Figure 2: Adjustment Paths, Selected Variables. Dashed line: $\lambda=0.25$. Solid line: $\lambda=0.5$. Dotted line: $\lambda=0.75$. 
Figure 3: Output Adjustment Paths for $\rho=0.05$. Dashed line: $\lambda=0.25$. Solid line: $\lambda=0.5$. Dotted line: $\lambda=0.75$.

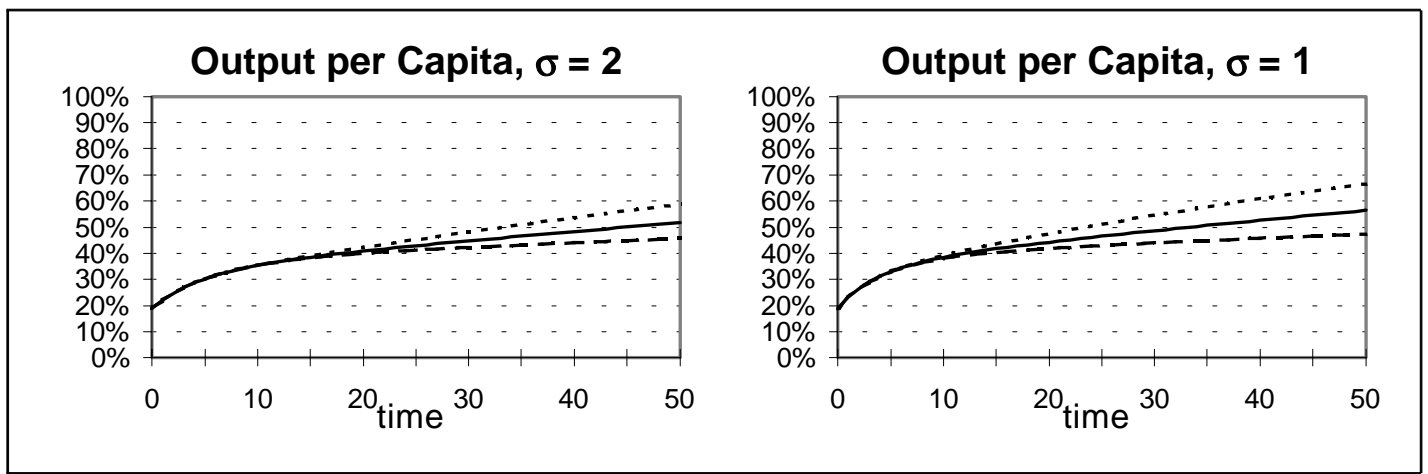

Figure 4: Inflation Adjusted Return in the Japanese Stock Market, 1955-1988. Source: Christiano (1989, Chart 4).

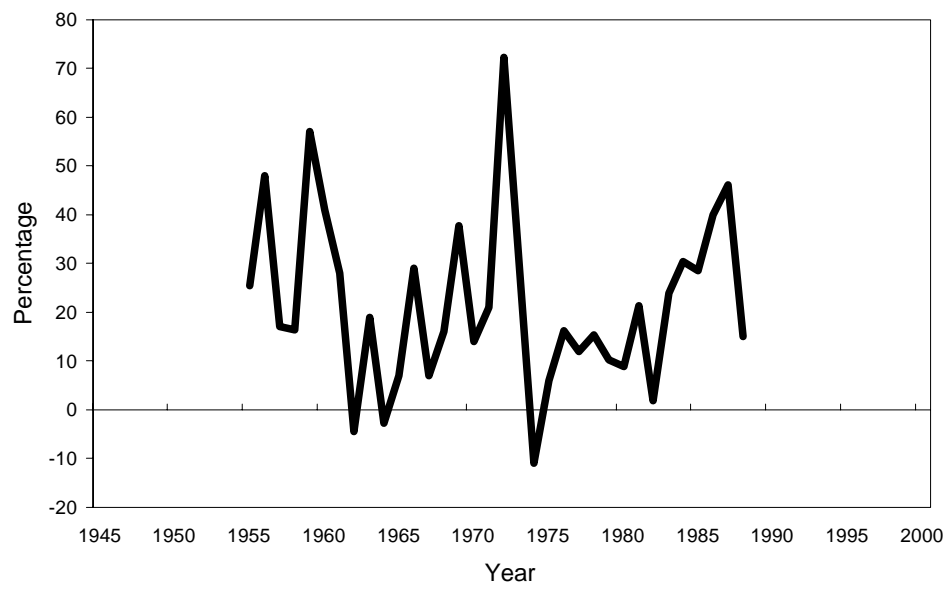




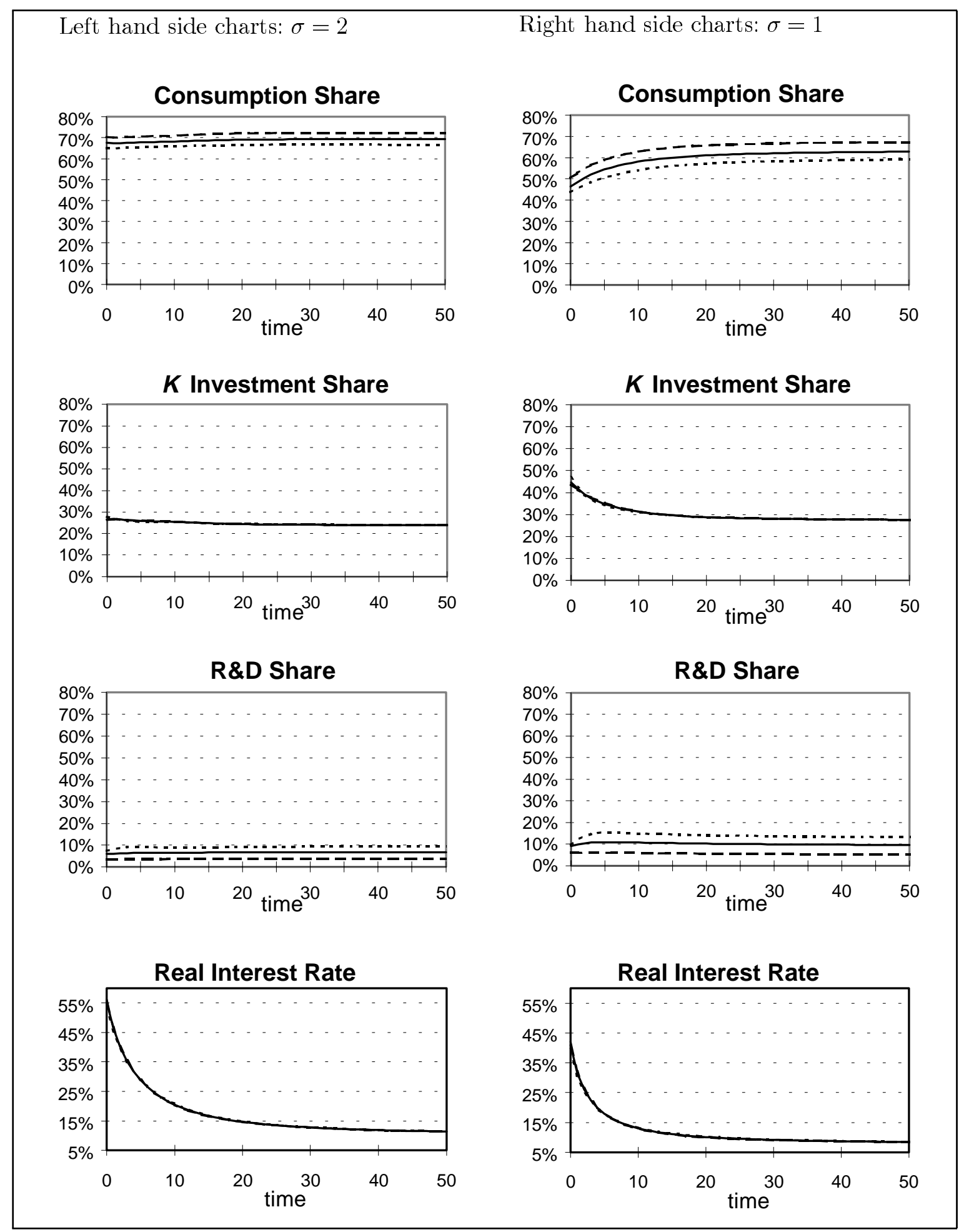

Figure 5: Adjustment Paths, Selected Variables. Dashed line: $\lambda=0.25$. Solid line: $\lambda=0.5$. Dotted line: $\lambda=0.75$. 